Acta Crystallographica Section B

Structural

Science

ISSN 0108-7681

\section{Modulated structure of nepheline}

The incommensurately modulated structure of a natural nepheline of composition $\mathrm{K}_{0.54} \mathrm{Na}_{3.24} \mathrm{Ca}_{0.03} \mathrm{Al}_{3.84} \mathrm{Si}_{4.16} \mathrm{O}_{16}$ has been determined in superspace. The compound crystallizes in the trigonal centered superspace group $X 3(00 \gamma) 0$ with $\gamma=$ 0.2048 (10), $X=(0,0,0,0),(1 / 3,2 / 3,0,2 / 3),(2 / 3,1 / 3,0,1 / 3), a=$ $17.2889(8)$ and $c=8.3622(10) \AA$. The structure is characterized by a framework of corner-connected $(\mathrm{Al}, \mathrm{Si}) \mathrm{O}_{4}$ tetrahedra. The additional cations are incorporated in two different types of channels of the framework. All atoms in the structure are displacively modulated with amplitudes below $0.1 \AA$. The modulation can be well described taking into account harmonics of first order only. Atomic positions in the smaller channels of the framework are fully occupied by $\mathrm{Na}^{+}$. Cationic positions in the larger channel are occupationally modulated, yet the variation of electron density as a function of the internal coordinate $t$ is very small and indicates that the incorporation of different types of cations $\left(\mathrm{K}^{+}, \mathrm{Na}^{+}, \mathrm{Ca}^{2+}\right)$ and vacancies is realised in a highly disordered way. Average $T-\mathrm{O}$ distances indicate a nearly complete $\mathrm{Al} / \mathrm{Si}$ ordering in the tetrahedral framework. A large part of the $\mathrm{O}$ atoms are approximated by split-atom positions, which are additionally affected by occupational modulation resulting in a high degree of disorder in the modulated structure. Occupational probabilities for the split-atom positions are complementary. Occupational modulations of the cations in the larger channels and the $\mathrm{O}$ atoms of the tetrahedral framework are coupled and correlations between occupational and displacive modulations exist.

\section{Introduction}

Modulated structures are commonly observed in minerals. Prominent examples are the intermediate plagioclase feldspars (Yamamoto et al., 1984; Steurer \& Jagodzinski, 1988), minerals from the sodalite group (Hassan \& Buseck, 1989; Xu \& Veblen, 1995; Hassan, 2000; Hassan et al., 2004; Bolotina, 2006; Bolotina et al., 2006) and melilites (Schaper et al., 2001; Bindi, Bonazzi et al., 2001; Bindi, Czank et al., 2001; Bindi \& Bonazzi, 2003; Merlini et al., 2005; Bindi \& Bonazzi, 2005; Bindi et al., 2006). In general, owing to the high flexibility in the chemical composition of minerals, occupational modulations are very frequent and play a prominent role in the formation of modulated mineral structures.

Natural nepheline, a feldspathoid and an important rockforming mineral has been known to form an incommensurately modulated structure since satellite reflections were first observed in a sample from Finland (Sahama, 1958).

The average structure of natural nepheline was first described by Hahn \& Buerger (1955) and later redetermined by other authors (Gregorkiewitz, 1984; Hassan et al., 2003; Tait
Received 1 July 2010 Accepted 3 December 2010
(C) 2011 International Union of Crystallography Printed in Singapore - all rights reserved 
et al., 2003; Angel et al., 2008). The symmetry of the average structure is given as $P 6_{3}$ with lattice parameters $a \simeq 10$ and $c \simeq 8.3 \AA$. Even at pressures up to $7.5 \mathrm{GPa}$ the hexagonal lattice is maintained (Gatta \& Angel, 2007).

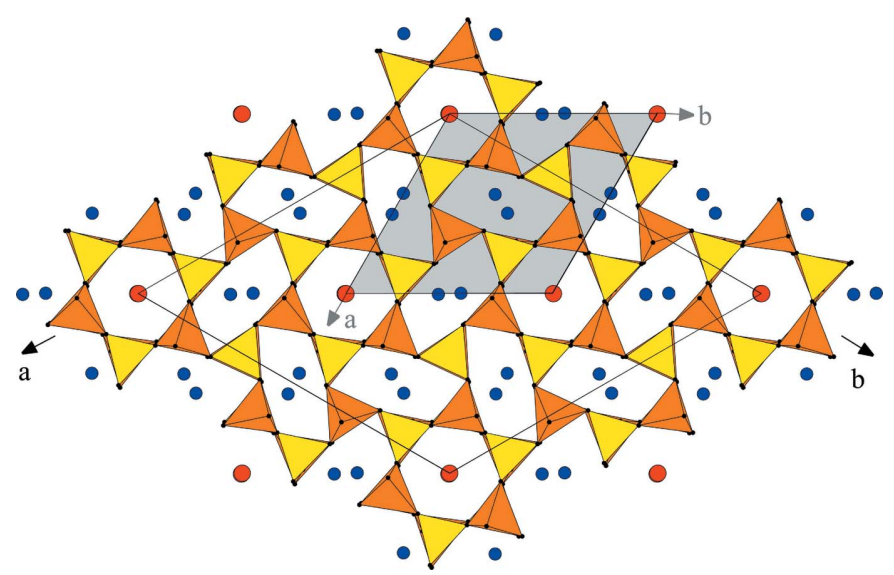

Figure 1

Average structure of nepheline in space group $P 6_{3}$. The tetrahedra around $\mathrm{Si}$ are indicated in yellow, the tetrahedra around $\mathrm{Al}$ in orange. $\mathrm{Na}$ in the smaller, oval channel is shown in blue, cations $(\mathrm{K}, \mathrm{Na}, \mathrm{Ca})$ in the larger, pseudohexagonal channel are shown in red. The smaller unit cell indicated in grey corresponds to the primitive one used in the literature, the larger unit cell is the centered cell on which the superspace refinement is based. Split-atom positions are not shown for sake of clarity.
The structure is characterized by a framework of cornerconnected $(\mathrm{Al}, \mathrm{Si}) \mathrm{O}_{4}$ tetrahedra and can be considered as a stuffed derivative of tridymite (Fig. 1). Two different types of six-membered rings of tetrahedra are arranged parallel to (001). The larger one has a nearly regular hexagonal shape, while the smaller one is pseudo-orthorhombic and assumes an oval shape. Layers of these tetrahedral rings are stacked along [001] to form a three-dimensional framework. Previous investigations agree on the fact that the $\mathrm{Si}^{4+} / \mathrm{Al}^{3+}$ distribution within the framework is characterized by a high degree of order (Sahama, 1962; Dollase \& Peacock, 1971; Dollase \& Thomas, 1978; Gregorkiewitz, 1984; Stebbins et al., 1986; Tait et al., 2003). The non-framework cations are incorporated into the two channels formed by these rings. The smaller, oval channel is fully occupied by $\mathrm{Na}^{+}$, while the larger, pseudohexagonal channel is occupied by the larger $\mathrm{K}^{+}$and additional $\mathrm{Na}^{+}$or $\mathrm{Ca}^{2+}$. However, as the $\mathrm{K}$ content is usually limited to approximately $60 \%$ of the ideal occupation and no more than $20-25 \%$ of additional $\mathrm{Na}$ and $\mathrm{Ca}$ are incorporated, about $1 / 5$ of vacancies have to be taken into account for the channel. It is noteworthy that one of the $\mathrm{O}$ atoms (O1) located on a special position corresponding to a threefold rotation axis shows very large displacement parameters and is usually described with a split-atom position in the average structure.

The existence of additional satellite reflections in natural nepheline is well documented (Sahama, 1958; McConnell, $1962,1981)$. The modulation wavevector was determined to be $\mathbf{q}=( \pm 1 / 3, \pm 1 / 3, \gamma)$ with an incommensurate $\gamma$ value of $0.2+\delta$, with the exact value of $\delta$ depending on the chemical composition (McConnell, 1962). The temperature-dependent evolution of satellite reflections has been studied in detail by McConnell (1981) and Angel et al. (2008). A study on the evolution of the intensities of the satellite reflections under hydrostatic pressure has shown that these reflections disappear between 1 and $1.8 \mathrm{GPa}$ (Gatta \& Angel, 2007).

Different explanations have been proposed to be at the origin of the incommensurate modulation in nepheline:

(i) Ordering of the cation vacancies in the large, pseudohexagonal channel (Foreman \& Peacor, 1970; McConnell, 1981; Merlino, 1984).

(ii) Formation of domains with different $\mathrm{Al} / \mathrm{Si}$ ordering patterns (McConnell, 1962).

(iii) Displacive modulation of the essentially rigid tetrahedra of the framework (Parker \& McConnell, 1971; Parker, 1972; Hayward et al., 2000).
Figure 2

Schematic view of the $h k 0$ plane and corresponding satellite reflections of the diffraction pattern of nepheline. Part of the main reflections and satellite reflections belonging to twin individual I (green) are indexed with respect to the large centered unit cell. Satellite reflections belonging to twin individual II are shown in red. 
(iv) Coupling between the displacive modulation of the tetrahedral framework and the ordering of cations and vacancies in the pseudohexagonal channel (Angel et al., 2008).

However, up to now structural investigations on nepheline have been limited to the average structure and no full determination has been performed, taking into account the intensities of the satellite reflections. Given the importance of this rock-forming mineral, we therefore decided to carry out a full structure determination of the incommensurately modulated structure of nepheline in higher-dimensional space using the superspace algorithm (de Wolff, 1974; Janner \& Janssen, 1980a,b; de Wolff et al., 1981).

\section{Experimental}

The crystal studied originates from the intrusive aplite of Snipe River, Tambani, Nyasaland, Malawi, and is the sample investigated by other authors (McConnell, 1962, 1981; Gatta \& Angel, 2007; Angel et al., 2008). The exact composition was determined earlier as $\mathrm{K}_{0.54} \mathrm{Na}_{3.24} \mathrm{Ca}_{0.03} \mathrm{Al}_{3.84} \mathrm{Si}_{4.16} \mathrm{O}_{16}$ (McConnell, 1962).

A fragment $(\sim 0.12 \times 0.20 \times 0.43 \mathrm{~mm})$ of a larger single crystal was mounted on a glass pin and the diffracted intensities were measured at beamline D3 of the synchrotron HASYLAB/DESY (Hamburg) at a wavelength of $0.4 \AA$ using a Huber four-circle diffractometer in combination with a MarCCD165 detector. The use of synchrotron radiation was indispensable, as preliminary experiments on laboratory equipment showed the satellite reflections to be rather weak and not measurable in-house. Reciprocal space reconstructions on the basis of the measured data showed no additional diffuse scattering (selected reconstructions are supplied in the supplementary material). The data were integrated with the program EVAL15 (Schreurs et al., 2010) and a numerical absorption correction was applied with the program JANA2006 (Petříček et al., 2006).

\section{Interpretation of the diffraction pattern and superspace embedding}

The intensities of the satellite reflections in nepheline are extremely weak. Referring to a basis with $\mathbf{a}_{\mathrm{P}}=\mathbf{b}_{\mathrm{P}} \simeq 10 \AA$ and $\mathbf{c}_{\mathrm{P}} \simeq 8.36 \AA$ they can be indexed by two $\mathbf{q}$ vectors, $\mathbf{q}_{1}=(1 / 3,1 / 3,0.2048)$ and $\mathbf{q}_{2}=(1 / 3,1 / 3,-0.2048)$. In principle, the observed diffraction pattern suggests two possible interpretations:

(i) the structure is $(3+2)$-dimensional and requires two $\mathbf{q}$ vectors to index all the satellite reflections;

(ii) the structure is $(3+1)$-dimensional and the crystal is twinned.

In the first model one expects to find satellite reflections at positions resulting from combinations of $\mathbf{q}_{1}$ and $\mathbf{q}_{2}$. Inspection of reciprocal space sections and trial integrations at these positions showed, however, that this is not the case. On the other hand, a $(3+1)$-dimensional model with $\mathbf{q}_{1}=(1 / 3,1 / 3,0.2048)$ and an additional twinning operation does explain the observed distribution of satellite reflections.
Two twinning operations are equally probable for this description: either a mirror plane perpendicular to the $c$ axis [described by the matrix $(100 ; 010 ; 00 \overline{1})$ ] or a twofold rotation around $c$ [described by the matrix $(\overline{100} ; 0 \overline{1} 0 ; 001)]$. Of the two, the mirror plane perpendicular to $c$ was chosen in our description.

To avoid a $\mathbf{q}$ vector with rational components we chose a $3^{1 / 2} \times 3^{1 / 2} \times 1$ supercell for indexing the main reflections $\left[\mathbf{a}_{X}=\mathbf{b}_{X}=17.2889\right.$ (8) $\AA$ and $\mathbf{c}_{X}=8.3622$ (10) $\AA$ ]. The relation between the two unit cells is given by $\mathbf{a}_{X}=\mathbf{a}_{P}-\mathbf{b}_{P}$, $\mathbf{b}_{X}=\mathbf{a}_{P}+2 \mathbf{b}_{P}$ and $\mathbf{c}_{X}=\mathbf{c}_{P}$. Both unit cells are indicated in Fig. 1 . With this choice the $\mathbf{q}$ vector is given by $(0,0,0.2048)$ and diffracted intensities were integrated accordingly with the program EVAL15 (Schreurs et al., 2010). Integration showed that satellite reflections of second or higher order had no significant intensity. In the centered unit cell only reflections with $h-k-m=3 n$ and $h-k+m=3 n$ are observed in the diffraction pattern. Reflections fulfilling the first reflection condition belong to the first twin individual, reflections fulfilling the second condition belong to the second twin individual. The observed extinction rules for one individual correspond to a superspace centering with $X=(0,0,0,0),(1 / 3,2 / 3,0,2 / 3),(2 / 3,1 / 3,0,1 / 3)$. Fig. 2 represents a schematic drawing of reciprocal space of nepheline illustrating the indexing. ${ }^{\mathbf{1}}$ The main reflections of the two twin individuals overlap and are indicated in black, while satellite reflections are shown in green (first individual) or red (second individual).

As mentioned above, the average structure of nepheline is described in the literature in space group $P 6_{3}$. However, if one takes into account main and satellite reflections, using a hexagonal superspace group in $(3+1)$-dimensional space is impossible. This is basically due to the fact that the set of translations corresponding to superspace centering $X=(0,0,0,0),(2 / 3,1 / 3,0,1 / 3)$ and $(1 / 3,2 / 3,0,2 / 3)$ are not compatible with the twofold screw axis, as the two nonprimitive vectors would be transformed by the twofold screw axis to $(1 / 3,2 / 3,0,1 / 3)$ and $(2 / 3,1 / 3,0,2 / 3)$. Together with the original centering vectors this leads to a set of vectors which is not in accordance with the observed extinction rules.

The threefold rotation axis, however, is perfectly compatible with the observed centering. The superspace group $X 3(00 \gamma) 0$ is therefore an obvious choice for the refinement of the incommensurate structure.

\section{Structure refinement}

\subsection{Average structure in space group $P_{3}$}

To compare our data with the results obtained in earlier studies we first performed a refinement of the average structure in the space group $P 6_{3}$ using the small primitive unit cell as a basis (Table 1). It should be pointed out that compared with earlier studies we measured a significantly larger number of reflections and achieved a superior atomic resolution

\footnotetext{
${ }^{1}$ Selected reconstructed reciprocal planes are provided in the supplementary material.
} 
Table 1

Details for the refinement of the average structure (using only intensities of the main reflections) in $P 6_{3}$ and $P 3$.

For all structures: $\mathrm{K}_{0.54} \mathrm{Na}_{3.24} \mathrm{Ca}_{0.03} \mathrm{Al}_{4} \mathrm{Si}_{4} \mathrm{O}_{16}, M_{\mathrm{r}}=573$. Experiments were carried out at $293 \mathrm{~K}$. Refinement was with 0 restraints.

\begin{tabular}{lll}
\hline & $P 6_{3}$ & $P 3$ \\
\hline Crystal data & & \\
Cell setting, space group & Hexagonal, $P 6_{3}$ & Trigonal, $P 3$ \\
$a, c(\AA)$ & $9.9818(4), 8.3622(10)$ & $9.9818(4), 8.3622(10)$ \\
$V\left(\AA^{3}\right)$ & $721.55(10)$ & $721.55(10)$ \\
$Z$ & 2 & 2 \\
No. of reflections for unit-cell parameter & 12279 & 12279 \\
$\theta$ range & $1.5-27.6$ & $1.5-27.6$ \\
$\mu\left(\mathrm{mm}^{-1}\right)$ & 0.21 & 0.21 \\
Data collection & & \\
Diffractometer & Huber four-circle & \\
Absorption correction & Numerical $J A N A 2006$ & Huber four-circle \\
$T_{\min }, T_{\max }$ & $0.872,0.960$ & Numerical $J A N A 2006$ \\
No. of measured, independent and & $112979,5265,4288$ & $0.872,0.960$ \\
$\quad$ observed $[I>3 \sigma(I)]$ reflections & & $113039,10240,7981$ \\
$R_{\text {int }}$ & 0.066 & \\
Refinement & & 0.065 \\
$R\left[F^{2} \geq 3 \sigma\left(F^{2}\right)\right], w R\left(F^{2}\right), S \dagger$ & $0.045,0.061,3.45$ & \\
No. of reflections & 5265 & $0.038,0.047,2.38$ \\
No. of parameters & 91 & 10240 \\
$\Delta \rho_{\max }, \Delta \rho_{\min }\left(\mathrm{e} \AA \AA^{-3}\right)$ & $1.20,-1.66$ & 164 \\
\hline
\end{tabular}

Computer programs used: EVAL15 (Schreurs et al., 2010), JANA2006 (Petř́ćcek et al., 2006), ATOMS5.0.7 (Dowty, 1997). $\dagger$ Agreement factors for data limited to $\sin \theta / \lambda=0.85: R[F \geq 3 \sigma(F)]: 0.0338\left(P 6_{3}\right)$ and $0.0268(P 3) ; w R(F): 0.0523$ $\left(P 6_{3}\right)$ and $0.0365(P 3)$.

$\left(\sin \theta / \lambda=1.15 \AA^{-1}\right)$. The starting coordinates for the refinement were taken from Hahn \& Buerger (1955). The refinement took into account the atomic coordinates, anisotropic displacement parameters, the overall scale factor and an isotropic extinction correction (Becker \& Coppens, 1974). A twin refinement with an inversion center as an additional twin operation did lead to large errors on the twin volume fractions. This is understandable because the imaginary parts of the anomalous scattering correction terms for all atomic types are smaller than 0.1. Despite the large number of measured Friedel pairs, the refinement of an inversion twin model was therefore discarded.

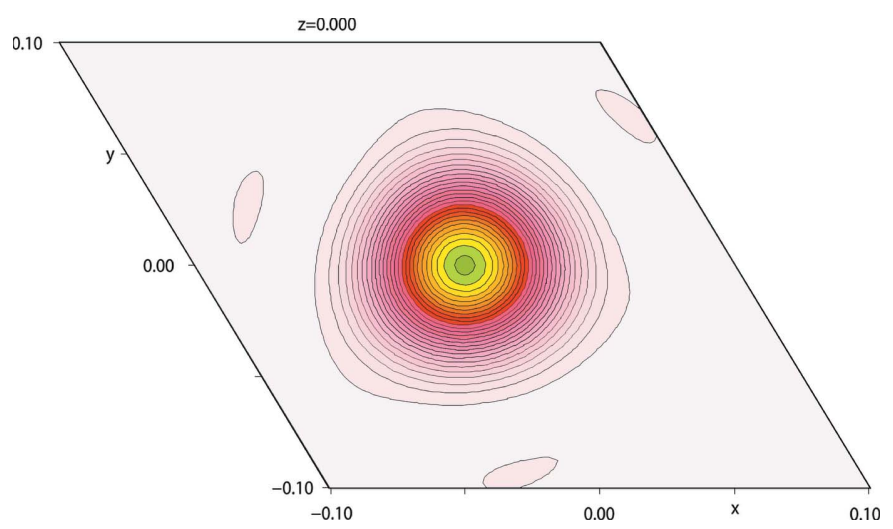

Figure 3

$F($ obs ) Fourier map around the $\mathrm{K} 1$ position corresponding to the refinement of the average structure in $P 6_{3}$ (contour lines 1.5 e $\AA^{-3}$ ).
The final structural model in $P 6_{3}$ is in agreement with earlier investigations and we therefore abstain here from a detailed discussion. ${ }^{2}$ We would only like to point out several characteristics of the average structure, which are relevant for the subsequent determination of the modulated structure:

(i) The average distances in the tetrahedra indicate a complete $\mathrm{Al} / \mathrm{Si}$ ordering. No clear indication as to which sites incorporate the excess $\mathrm{Si}^{4+}$ can be obtained from the average structure.

(ii) There is no indication of a deviation of the Na occupancies in the small, oval channels from the ideal value.

(iii) A refinement of the occupation parameter of the cation site in the large, pseudohexagonal channel corresponds to an electron density which is in good agreement with the chemical composition, i.e. a mixed occupancy of $0.54 \mathrm{~K}^{+}+0.24 \mathrm{Na}^{+}+$ $0.03 \mathrm{Ca}^{2+}$, in combination with 0.19 vacancies.

(iv) The oxygen atom (O1) on the threefold rotation axis has extremely high displacement parameters and is best modeled using a split-atom position slightly shifted from the special position.

(v) The $F$ (obs) Fourier map around the $\mathrm{K}$ position in the large, pseudohexagonal channels reveals a small anharmonic effect in the refinement of the average structure (Fig. 3), which to our knowledge was not reported in earlier investigations. This observation might indicate that the cations in this channels are slightly displaced from the threefold rotation axis.

\subsection{Incommensurately modulated structure}

As mentioned in $\$ 3$ if one takes into account not only the main but also the satellite reflections the diffraction diagram of nepheline is not in accordance with a twofold rotation axis. The threefold rotation axis, however, implies no such problems. We therefore transformed the coordinates of the average structure in $P 6_{3}$ to a model in $P 3$, which follows on the basis of group-subgroup relationships. The refinement of the modulated structure in the superspace group $X 3(00 \gamma) 0$ was started from atomic coordinates obtained this way (see Table 2 for further details concerning the refinement). As explained in $\S 3$, two possible twin operations allow all satellite reflections to

\footnotetext{
${ }^{2}$ Supplementary data for this paper, including details about all refinements, coordinates and displacement parameters, are available from the IUCr electronic archives (Reference: CK5042). Services for accessing these data are described at the back of the journal.
} 
Table 2

Experimental details for the incommensurate structure of nepheline.

\begin{tabular}{|c|c|}
\hline \multicolumn{2}{|l|}{ Crystal data } \\
\hline Chemical formula & $\mathrm{K}_{0.54} \mathrm{Na}_{3.24} \mathrm{Ca}_{0.03} \mathrm{Al}_{4} \mathrm{Si}_{4} \mathrm{O}_{16}$ \\
\hline$M_{\mathrm{r}}$ & 573 \\
\hline Cell setting, superspace group & Trigonal, $X 3(00 \gamma) 0 \dagger$ \\
\hline Temperature $(\mathrm{K})$ & 293 \\
\hline Modulation wavevector & $\mathbf{q}=0.2048(10) \mathbf{c}^{*}$ \\
\hline Centering & $\begin{array}{l}(0,0,0,0),(1 / 3,2 / 3,0,2 / 3) \\
\quad(2 / 3,1 / 3,0,1 / 3)\end{array}$ \\
\hline$a, c(\AA)$ & $17.2889(8), 8.3622(10)$ \\
\hline$V\left(\AA^{3}\right)$ & $2164.6(3)$ \\
\hline$Z$ & 6 \\
\hline Radiation source & Synchrotron, $\lambda=0.4 \AA$ \\
\hline$\mu\left(\mathrm{mm}^{-1}\right)$ & 0.21 \\
\hline Crystal form, size (mm) & Irregular, $0.12 \times 0.20 \times 0.43$ \\
\hline \multicolumn{2}{|l|}{ Data collection } \\
\hline Diffractometer & Huber four-circle \\
\hline Absorption correction & Numerical JANA2006 \\
\hline$T_{\min }, T_{\max }$ & $0.872,0.960$ \\
\hline $\begin{array}{l}\text { No. of measured, independent and } \\
\text { observed }[I>3 \sigma(I)] \text { reflections }\end{array}$ & $569470,24784,11997$ \\
\hline$R_{\text {int }}$ & 0.083 \\
\hline \multicolumn{2}{|l|}{ Refinement } \\
\hline$R[F \geq 3 \sigma(F)]$ (all, main, sat) & $0.0380,0.0273,0.0765$ \\
\hline$w R(\bar{F})$ (all, main, sat) & $0.0510,0.0375,0.0899$ \\
\hline$S($ all $)$ & 2.35 \\
\hline No. of parameters & 282 \\
\hline Maximum $\sin \theta / \lambda\left(\AA^{-1}\right)$ & 0.85 \\
\hline$\Delta \rho_{\max }, \Delta \rho_{\min }\left(\mathrm{e} \AA^{-3}\right)$ & $1.50,-0.74$ \\
\hline Twin matrix & $(100),(010),(00 \overline{1})$ \\
\hline Twin volume fractions & $0.4984(8): 0.5016(8)$ \\
\hline Absolute structure & $\begin{array}{l}7433 \text { of Friedel pairs used in the } \\
\text { refinement }\end{array}$ \\
\hline
\end{tabular}

Computer programs used: see Table 1. $\dagger$ Symmetry operations: (i) $x_{1}, x_{2}, x_{3}, x_{4}$; (ii) $-x_{2}, x_{1}-x_{2}, x_{3}, x_{4}$; (iii) $-x_{1}+x_{2},-x_{1}, x_{3}, x_{4}$; (iv) $x_{1}+1 / 3, x_{2}+2 / 3, x_{3}, x_{4}+2 / 3$; (v) $-x_{2}+1 / 3, x_{1}-x_{2}+2 / 3, x_{3}, x_{4}+2 / 3$; (vi) $-x_{1}+x_{2}+1 / 3,-x_{1}+2 / 3, x_{3}, x_{4}+2 / 3$; (vii) $x_{1}+2 / 3, x_{2}+1 / 3, x_{3}, x_{4}+1 / 3$; (viii) $-x_{2}+2 / 3, x_{1}-x_{2}+1 / 3, x_{3}, x_{4}+1 / 3$; (ix) $-x_{1}+x_{2}+2 / 3,-x_{1}+1 / 3, x_{3}, x_{4}+1 / 3$.

be indexed: either a mirror plane perpendicular to $\mathbf{c}$ or a twofold rotation around $\mathbf{c}$. In addition, as the structure is noncentrosymmetric the possibility of inversion twinning also needs to be taken into account. However, owing to the small values of the anomalous scattering correction terms, in a twin refinement taking into account four different individuals only the volume fractions of two individuals can be reliably determined. The possible choices for the twin operation are the twofold axis parallel to $\mathbf{c}$ or the mirror plane perpendicular to c. The latter operation was chosen by us. Still, it has to be pointed out that both choices lead to the same overall agreement factors and result in identical structures. For the refinement only reflections up to $\sin \theta / \lambda=0.85 \AA^{-1}$ were used, as at higher $\theta$ values the percentage of observed satellite reflections was decreasing rapidly.

The great similarity to the centrosymmetric superspace group $X \overline{3}(00 \gamma) 0$ gave rise to correlations in the refinement. ${ }^{3}$ To reduce them to a minimum, additional restraints were introduced. For this a local symmetry operation corresponding to a center of symmetry was defined and used to introduce

\footnotetext{
${ }^{3}$ A refinement in the centrosymmetric superspace group $X \overline{3}(00 \gamma) 0$, where an ordered distribution of the tetrahedral cations is not possible, was also carried out. The agreement factors, however, are significantly better for the noncentrosymmetric superspace group than for the centrosymmetric one.
}

restraints between atomic positions, which would be equivalent in the centrosymmetric structure and which showed refined parameters in accordance with this local symmetry operation. A list of all restraints used in the refinement is given in the supplementary material. In general, pairs of atoms related by the (pseudo)inversion center are designated by identical numbers, followed by ' $a$ ' and ' $b$ '.

Displacive modulation was introduced for all atoms. Refinement showed that it was sufficient to take into account the first harmonics of the modulation functions; refinement of second harmonics led to values not significantly different from zero for all atoms.

As expected, we found no indications that the Na-atom positions in the smaller, oval channels were affected by an occupational modulation. For the atomic sites in the large, pseudohexagonal channel (in the following referred to as $\mathrm{K} 1 \mathrm{a}$ and $\mathrm{K} 1 \mathrm{~b})$ we assumed mixed occupancies of $0.57 \mathrm{~K}^{+}$ $\left(\sim 0.54 \mathrm{~K}^{+}+0.03 \mathrm{Ca}^{2+}\right)$ and $0.24 \mathrm{Na}^{+}$as deduced from the chemical composition. Initially the $\mathrm{K} 1 \mathrm{a}$ and $\mathrm{K} 1 \mathrm{~b}$ atoms were placed on the threefold axis. The Fourier synthesis around the $\mathrm{K} 1 \mathrm{a}$ and $\mathrm{K} 1 \mathrm{~b}$ atom positions showed a clear indication of a displacive modulation in the direction of $x_{3}$ together with a small fluctuation of the electron density (Fig. 4) as a function of the internal coordinate $t$ (representing the phase of the modulation). Consequently an occupational modulation was introduced. Various ways of modeling the observed electron density were tried (i.e. higher harmonics, crenel functions). In the end, a simple occupational modulation function taking into account harmonics of first order only proved to give the best results. At this stage, difference Fourier synthesis still revealed discrepancies between the observed density and the
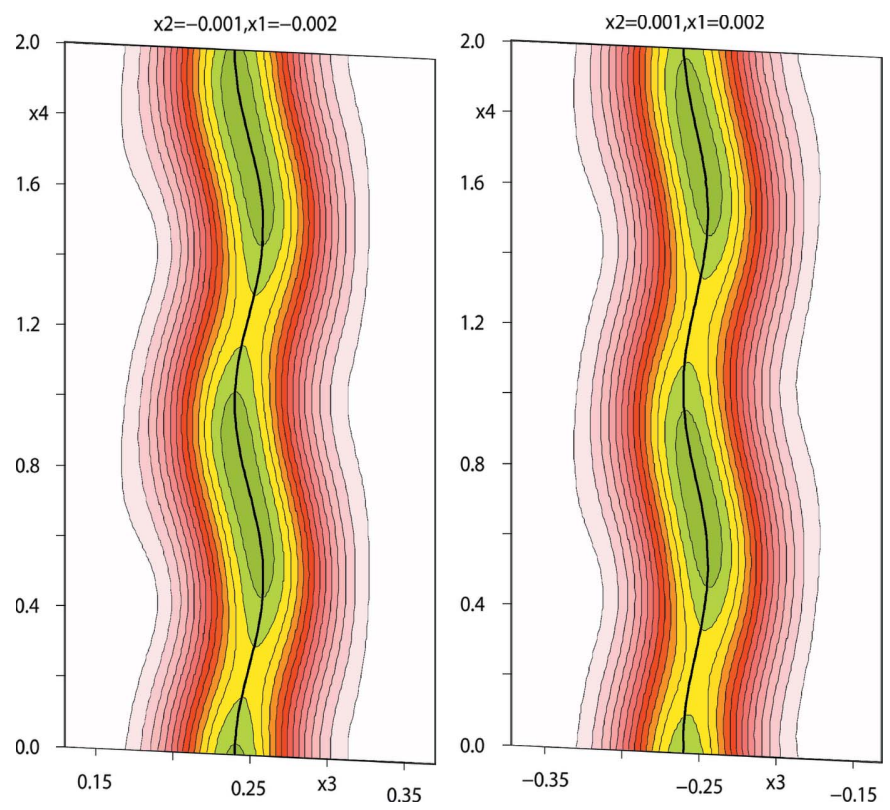

Figure 4

$F$ (obs) Fourier map around the K1a and K1b position. Scope of the maps: $x_{1}=-0.0018, x_{2}=-0.0015, x_{3}=0.1304-0.3696, x_{4}=0.0-2.0$ and $x_{1}=$ $0.0018, x_{2}=0.0015, x_{3}=-0.3711$ to $-0.1320, x_{4}=0.0-2.0$ (contour lines $3 \mathrm{e} \AA^{-3}$ ). The refined modulation functions for $\mathrm{K} 1 \mathrm{a}$ and $\mathrm{K} 1 \mathrm{~b}$ are indicated. 
Table 3

Occupational modulation amplitudes in nepheline [superspace group $X 3(00 \gamma) 0]$.

The groups of atoms $\mathrm{O} 2 \mathrm{a} / \mathrm{O} 2 \mathrm{~b} 1 / \mathrm{O} 3 \mathrm{a} 1 / \mathrm{O} 3 \mathrm{~b} 1 / \mathrm{O} 4 \mathrm{a} 1 / \mathrm{O} 4 \mathrm{~b} 1$ and $\mathrm{O} 2 \mathrm{a} 2 / \mathrm{O} 2 \mathrm{~b} 2 /$ $\mathrm{O} 3 \mathrm{a} 2 / \mathrm{O} 3 \mathrm{~b} 2 / \mathrm{O} 4 \mathrm{a} 2 / \mathrm{O} 4 \mathrm{~b} 2$ are modulated identically. The two different groups are modulated complementary. O6a and O6b are modulated complementary. Occupancies for the cationic positions were taken from the chemical composition and not refined.

\begin{tabular}{lllr}
\hline Atom & Occupancy & \multicolumn{1}{c}{ osin 1} & \multicolumn{1}{c}{ ocos 1} \\
\hline K1a + Na1a & $0.57+0.24$ & $-0.033(3)$ & 0 \\
K1b + Na1b & $0.57+0.24$ & $-0.019(3)$ & 0 \\
O1a & $1 / 3$ & $-0.101(6)$ & $-0.150(4)$ \\
O1b & $1 / 3$ & $0.176(4)$ & $-0.042(5)$ \\
O2a1 & 0.6692 & $-0.1980(16)$ & $0.056(3)$ \\
O2a2 & 0.3308 & $0.1981(16)$ & $-0.056(3)$ \\
O2b1 & 0.6692 & $-0.1925(17)$ & $-0.073(3)$ \\
O2b2 & 0.3308 & $0.1922(17)$ & $0.074(3)$ \\
O3a1 & 0.6692 & $-0.174(2)$ & $0.110(3)$ \\
O3a2 & 0.3308 & $0.167(2)$ & $-0.120(3)$ \\
O3b1 & 0.6692 & $-0.158(2)$ & $-0.132(3)$ \\
O3b2 & 0.3308 & $0.165(2)$ & $0.124(3)$ \\
O4a1 & 0.6692 & $-0.2054(14)$ & $-0.014(3)$ \\
O4a2 & 0.3308 & $0.2059(14)$ & $0.000(3)$ \\
O4b1 & 0.6692 & $-0.2057(14)$ & $-0.008(3)$ \\
O4b2 & 0.3308 & $0.2048(15)$ & $0.021(3)$ \\
\hline
\end{tabular}

adjusted model. The maxima in the difference Fourier maps suggested displacive modulation of the cations in the direction of $x_{1}$ and $x_{2}$, which are forbidden if the cations are located on the threefold axis. However, as mentioned above, even in the average structure the observed anharmonicity provides an indication that the cations in the large, hexagonal channels are slightly displaced from the special position and consequently we moved the atoms slightly off the $0,0, x_{3}$ positions. Starting values for $x_{1}$ and $x_{2}$ were obtained from a difference-Fourier synthesis and in the subsequent refinement cycles amplitudes of displacive modulation in the directions of $x_{1}$ and $x_{2}$ were refined. This led to a satisfactory approximation of the electron density for the cations (Fig. 5).

As already suggested by the refinement of the average structure, the oxygen atoms (O1a and O1b) located on the special position $1 / 3,1 / 3, \pm z$ are shifted away from the threefold axis. The electron density and difference-Fourier synthesis showed three distinct maxima around the ideal coordinates for both $\mathrm{O} 1 \mathrm{a}$ and $\mathrm{O} 1 \mathrm{~b}$; the relative weights of the maxima change as a function of $t$ (Fig. 6). Accordingly, in addition to a displacive modulation, an occupational modulation was introduced. The separation of the maxima was not large enough to justify the use of a crenel function. The introduction of occupational modulation for these positions
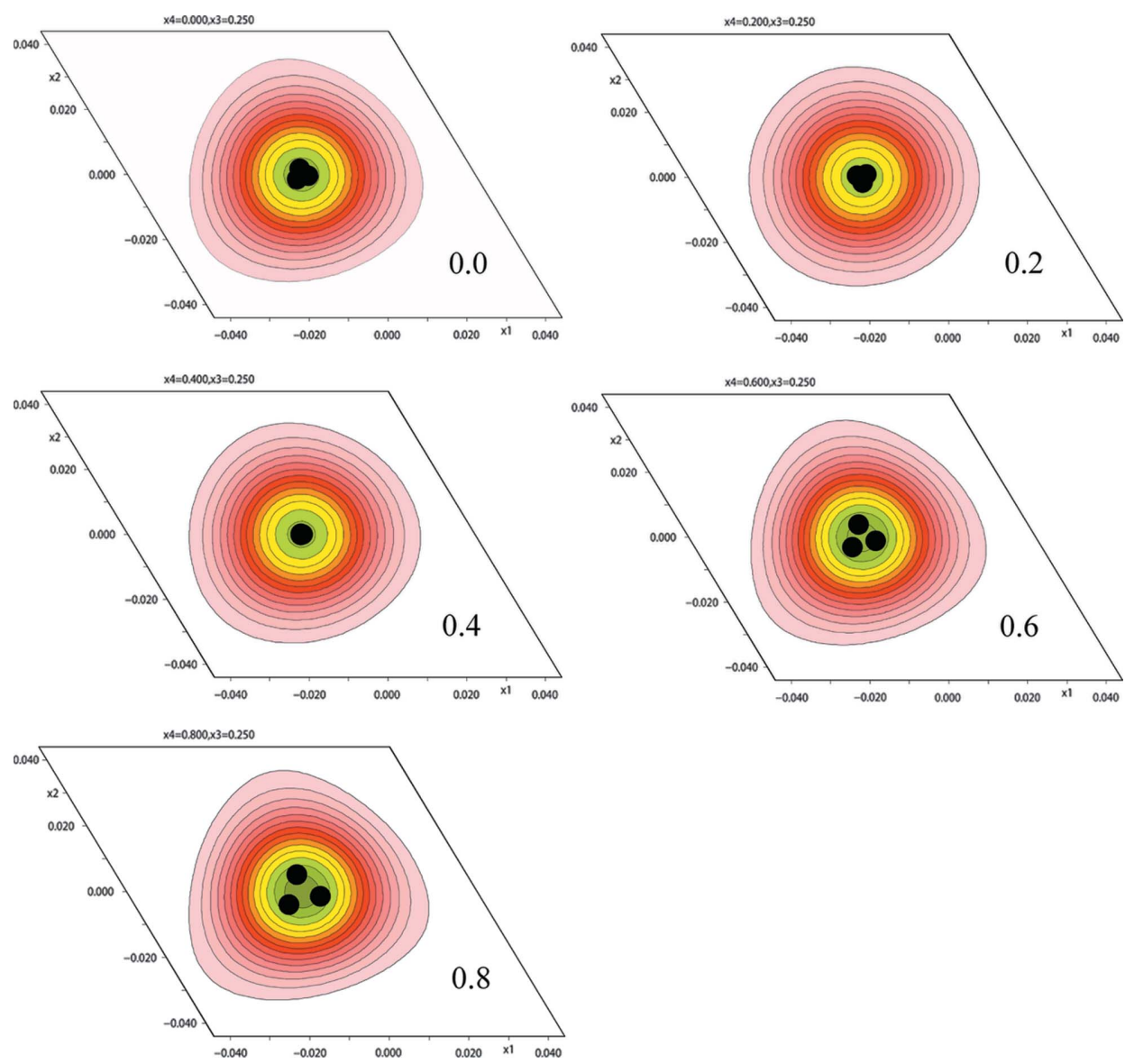

Figure 5

$F(\mathrm{obs})$ Fourier maps around the K1a position. Cuts are at different values of $t(0,0.2,0.4,0.6,0.8)$. The three symmetry-equivalent K1a positions are indicated. led to a considerable improvement in the agreement factors of the satellite reflections [more than $1.2 \%$ for $w R(F)]$.

At this stage, the large anisotropic atomic displacement parameters of other $\mathrm{O}$ atoms $(\mathrm{O} 2 \mathrm{a} / \mathrm{b}$, $\mathrm{O} 3 \mathrm{a} / \mathrm{b}, \mathrm{O} 4 \mathrm{a} / \mathrm{b}$ ) and differenceFourier syntheses suggested a similar description for these atoms. However, in these cases, only two maxima could be distinguished from the difference-Fourier maps (denoted O2a1/O2a2, O2b1/O2b2 etc.). An occupational modulation was introduced for the atoms and the corresponding sites were modulated as complementary, keeping the sum of occupation probabilities at the ideal value of 1 . Refinement showed that the resulting 12 oxygen positions formed two groups of six, with the atoms in each group behaving similarly. Group I was composed of atoms O2a1, O2b1, O3a1, O3b1, O4a1, O4b1; group II of atoms O2a2, O2b2, O3a2, O3b2, $\mathrm{O} 4 \mathrm{a} 2$, O4b2. Atoms within one group were modulated identically, as refinement showed the parameters to be equal within 
Table 4

Average, minimum and maximum $T-\mathrm{O}$ distances in the tetrahedra of nepheline [superspace group $X 3(00 \gamma) 0]$.

\begin{tabular}{|c|c|c|c|c|c|c|c|}
\hline Distance & Average & Minimum & Maximum & Distance & Average & Minimum & Maximum \\
\hline Al1 $-\mathrm{O} \mathrm{b}^{\mathrm{i}} \times 3$ & $1.696(5)$ & $1.693(5)$ & $1.700(5)$ & $\mathrm{Si} 1-\mathrm{O} 1 \mathrm{a}^{\mathrm{ii}} \times 3$ & $1.651(4)$ & $1.638(4)$ & $1.666(4)$ \\
\hline $\mathrm{Al} 1-\mathrm{O} 4 \mathrm{~b} 1 \times 3$ & $1.715(4)$ & $1.712(4)$ & $1.718(4)$ & $\mathrm{Si} 1-\mathrm{O} 4 \mathrm{a} 1 \times 3$ & $1.570(3)$ & $1.536(3)$ & $1.603(3)$ \\
\hline $\mathrm{Al} 1-\mathrm{O} 4 \mathrm{~b} 2 \times 3$ & $1.794(6)$ & $1.740(6)$ & $1.847(6)$ & $\mathrm{Si} 1-\mathrm{O} 4 \mathrm{a} 2 \times 3$ & $1.654(7)$ & $1.642(7)$ & 1.666 (7) \\
\hline $\mathrm{Al} 2-\mathrm{O} 1 \mathrm{a} \times 3$ & $1.736(4)$ & $1.724(4)$ & 1.749 (4) & $\mathrm{Si} 2-\mathrm{O} 1 \mathrm{~b} \times 3$ & $1.627(5)$ & $1.625(5)$ & $1.630(5)$ \\
\hline $\mathrm{A} 12-\mathrm{O} 3 \mathrm{a} 1 \times 3$ & $1.758(6)$ & $1.731(6)$ & $1.785(6)$ & $\mathrm{Si} 2-\mathrm{O} 3 \mathrm{~b} 2 \times 3$ & $1.670(6)$ & & $1.720(6)$ \\
\hline $\mathrm{Al} 2-\mathrm{O} 3 \mathrm{a} 2 \times 3$ & $1.648(10)$ & $1.641(10)$ & $1.656(10)$ & $\mathrm{Si} 2-\mathrm{O} 3 \mathrm{~b} 1 \times 3$ & $1.617(4)$ & $1.594(4)$ & $1.644(4)$ \\
\hline $\mathrm{Al} 3-\mathrm{O} 2 \mathrm{a} 1$ & $1.744(6)$ & $1.720(7)$ & $1.769(7)$ & $\mathrm{Si} 3-\mathrm{O} 2 \mathrm{~b} 1$ & $1.594(5)$ & $1.572(5)$ & $1.617(5)$ \\
\hline $\mathrm{A} 13-\mathrm{O} 2 \mathrm{a} 2$ & 1.715 & 1.660 & 1.769 & $\mathrm{Si} 3-\mathrm{C}$ & (9) & (8) & $1.723(8)$ \\
\hline $\mathrm{Al} 3-\mathrm{O} 4 \mathrm{a} 1$ & $1.765(3)$ & 1.737 & $1.793(3)$ & $\mathrm{Si} 3-\mathrm{O} 4 \mathrm{~b} 1$ & $1.633(3)$ & & $1.638(3)$ \\
\hline $\mathrm{Al} 3-\mathrm{O} 4 \mathrm{a} 2$ & $1.714(7)$ & $1.698(7)$ & $1.730(7)$ & $\mathrm{Si} 3-\mathrm{O} 4 \mathrm{~b} 2$ & $1.550(4)$ & $1.507(4)$ & $1.593(4)$ \\
\hline $\mathrm{Al} 3-\mathrm{O} 5 \mathrm{a}$ & $1.724(4)$ & $1.719(4)$ & $1.730(4)$ & $\mathrm{Si} 3-\mathrm{O} 5 \mathrm{a}^{\mathrm{iii}}$ & $1.613(4)$ & 1.607 (4) & $1.618(4)$ \\
\hline $\mathrm{Al} 3-\mathrm{O} 5 \mathrm{~b}^{\mathrm{iii}}$ & & & $1.731(4)$ & & & & $1.618(4)$ \\
\hline Al4_-OPb1 & 1.744 & 1.70 & 1.784 & & 1.631 & $1.620(7)$ & $1.644(7)$ \\
\hline $\mathrm{A} 14-\mathrm{O} 2 \mathrm{~b} 2$ & $1.754(9)$ & $1.665(8)$ & $1.841(9)$ & $\mathrm{Si} 4-\mathrm{O} 2 \mathrm{a} 2$ & 1.619 (12) & $1.587(13)$ & $1.651(13)$ \\
\hline $\mathrm{A} 14-\mathrm{O} 3 \mathrm{~b} 1$ & $1.732(3)$ & $1.712(3)$ & $1.751(3)$ & $\mathrm{Si} 4-\mathrm{O} 3 \mathrm{a} 1^{\mathrm{iv}}$ & $1.617(4)$ & $1.607(4)$ & $1.626(4)$ \\
\hline $\mathrm{Al} 4-\mathrm{O} 3 \mathrm{~b} 2$ & $1.683(5)$ & $1.658(5)$ & $1.709(5)$ & $\mathrm{Si} 4-\mathrm{O} 3 \mathrm{a} 2^{\mathrm{iv}}$ & $1.659(7)$ & $1.647(7)$ & $1.674(8)$ \\
\hline $\mathrm{Al} 4-06 \mathrm{a}^{\mathrm{v}}$ & $1.718(4)$ & $1.708(4)$ & $1.729(4)$ & & $1.624(3)$ & $1.618(3)$ & $1.629(3)$ \\
\hline $\mathrm{Al} 4-\mathrm{O} 6 \mathrm{~b}$ & $1.720(3)$ & $1.719(3)$ & $1.721(3)$ & $\mathrm{Si} 4-\mathrm{O}^{\mathrm{iv}} \mathrm{b}^{\mathrm{i}}$ & $1.625(4)$ & $1.618(4)$ & $1.633(4)$ \\
\hline
\end{tabular}

Symmetry codes: (i) $x_{1}, x_{2}, x_{3}+1$; (ii) $x_{1}, x_{2}, x_{3}-1$; (iii) $-x_{2}, x_{1}-x_{2}, x_{3}$; (iv) $-x_{2}, x_{1}-x_{2}, x_{3}+1$; (v) $-x_{2}, x_{1}-x_{2}, x_{3}-1$.

Table 5

Average, minimum and maximum $\mathrm{K}-\mathrm{O}$ and $\mathrm{Na}-\mathrm{O}$ distances in the structure of nepheline [superspace group $X 3(00 \gamma) 0]$.

\begin{tabular}{|c|c|c|c|c|c|c|c|}
\hline Distance & Average & Minimum & Maximum & Distance & Average & Minimum & Maximum \\
\hline $\mathrm{K} 1 \mathrm{a}-\mathrm{O} 2 \mathrm{a} 1$ & 3.098 (7) & $2.964(9)$ & $3.233(9)$ & $\mathrm{K} 1 \mathrm{~b}-\mathrm{O} 2 \mathrm{~b} 1$ & $3.175(6)$ & $3.103(5)$ & $3.244(5)$ \\
\hline $\mathrm{K} 1 \mathrm{a}-\mathrm{O} 2 \mathrm{a} 1^{\mathrm{i}}$ & $3.062(12)$ & $3.001(16)$ & $3.123(16)$ & $\mathrm{K} 1 \mathrm{~b}-\mathrm{O} 2 \mathrm{~b} 1^{\mathrm{i}}$ & $3.140(10)$ & 3.007 (11) & 3.276 (11) \\
\hline $\mathrm{K} 1 \mathrm{a}-\mathrm{O} 2 \mathrm{a} 1^{\mathrm{ii}}$ & $3.050(7)$ & $3.005(9)$ & $3.096(10)$ & $\mathrm{K} 1 \mathrm{~b}-\mathrm{O} 2 \mathrm{~b} 1^{\mathrm{ii}}$ & $3.127(6)$ & $2.980(8)$ & $3.271(8)$ \\
\hline $\mathrm{K} 1 \mathrm{a}-\mathrm{O} 2 \mathrm{a} 2$ & $2.892(9)$ & $2.838(11)$ & $2.947(10)$ & $\mathrm{K} 1 \mathrm{~b}-\mathrm{O} 2 \mathrm{~b} 2$ & $892(10)$ & $2.823(12)$ & $2.961(12)$ \\
\hline $\mathrm{K} 1 \mathrm{a}-\mathrm{O} 2 \mathrm{a} 2^{\mathrm{i}}$ & $2.856(18)$ & 2.837 (19) & $2.876(19)$ & $\mathrm{K} 1 \mathrm{~b}-\mathrm{O} 2 \mathrm{~b} 2^{\mathrm{i}}$ & $2.856(16)$ & $2.78(2)$ & $2.93(2)$ \\
\hline $\mathrm{K} 1 \mathrm{a}-\mathrm{O} 2 \mathrm{a} 2^{\mathrm{ii}}$ & $2.844(10)$ & 2.809 (11) & $2.879(11)$ & $\mathrm{K} 1 \mathrm{~b}-\mathrm{O} 2 \mathrm{~b} 2^{\mathrm{ii}}$ & $2.845(10)$ & $2.748(13)$ & $2.945(12)$ \\
\hline $\mathrm{K} 1 \mathrm{a}-\mathrm{O} 5 \mathrm{a}$ & $3.003(4)$ & $2.953(4)$ & 3.054 (4) & $\mathrm{K} 1 \mathrm{~b}-\mathrm{O} 5 \mathrm{a}^{\mathrm{i}}$ & $3.558(5)$ & $3.435(6)$ & $3.682(6)$ \\
\hline $\mathrm{K} 1 \mathrm{a}-05 \mathrm{a}^{\mathrm{i}}$ & & $2.923(5)$ & & & & & 3.097 (5) \\
\hline $\mathrm{K} 1 \mathrm{a}-\mathrm{O} 5 \mathrm{a}^{\mathrm{ii}}$ & $2.983(6)$ & $2.958(5)$ & 3.009 (5) & $-05 b^{i}$ & & & \\
\hline K1a-O6a & 3.034 (4) & 2.997 (5) & $3.071(5)$ & $\mathrm{K} 1 \mathrm{~b}-\mathrm{O} 5 \mathrm{~b}^{\mathrm{ii}}$ & $3.013(6)$ & $2.998(5)$ & $3.028(6)$ \\
\hline $\mathrm{K} 1 \mathrm{a}-\mathrm{O} 6 \mathrm{a}^{\mathrm{i}}$ & $2.990(5)$ & $2.943(7)$ & $3.037(7)$ & $\mathrm{K} 1 \mathrm{~b}-\mathrm{O} 6 \mathrm{~b}$ & $2.998(4)$ & $2.956(5)$ & $3.041(5)$ \\
\hline $\mathrm{K} 1 \mathrm{a}-\mathrm{O} 6 \mathrm{a}^{\mathrm{ii}}$ & $3.012(6)$ & 3.005 (4) & 3.019 (4) & $\mathrm{K} 1 \mathrm{~b}-\mathrm{O} 6 \mathrm{~b}^{\mathrm{i}}$ & $2.956(5)$ & $2.847(7)$ & $3.064(7)$ \\
\hline $1 \mathrm{a}-06 \mathrm{~b}^{\mathrm{iii}}$ & & 3.47 & & & & & (6) \\
\hline $\mathrm{Na} 2 \mathrm{a}-\mathrm{O} 1 \mathrm{~b}^{\mathrm{iv}}$ & 2.657 (13) & $2.552(13)$ & $2.760(13)$ & $\mathrm{Na} 2 \mathrm{~b}-\mathrm{O} 1 \mathrm{a}^{\mathrm{v}}$ & $3.203(8)$ & $3.156(8)$ & $3.251(9)$ \\
\hline $\mathrm{Na} 2 \mathrm{a}-\mathrm{O} 1 \mathrm{~b}^{\mathrm{vi}}$ & $2.987(15)$ & $2.835(14)$ & $3.136(14)$ & $\mathrm{Na} 2 \mathrm{~b}-\mathrm{O} 1 \mathrm{a}^{\mathrm{vii}}$ & $3.236(12)$ & 3.168 (12) & $3.306(12)$ \\
\hline $\mathrm{Na} 2 \mathrm{a}-\mathrm{O} 1 \mathrm{~b}^{\text {viii }}$ & 3.279 (10) & 3.200 (11) & 3.357 (10) & $\mathrm{Na} 2 \mathrm{~b}-\mathrm{O} 1 \mathrm{a}^{\mathrm{v}}$ & $2.479(8)$ & $2.458(8)$ & $2.500(8)$ \\
\hline $\mathrm{Na} 2 \mathrm{a}-\mathrm{O} 2 \mathrm{a} 1$ & $2.469(6)$ & & $2.504(7)$ & $\mathrm{Na} 2 \mathrm{~b}-\mathrm{O}$ & & & $2.491(5)$ \\
\hline $\mathrm{a} 2 \mathrm{a}-\mathrm{O} 2 \mathrm{a} 2$ & $2.677(9)$ & 2.63 & & $\mathrm{Na} 2 \mathrm{~b}-\mathrm{O}$ & (9) & & $2.733(9)$ \\
\hline $\mathrm{Na} 2 \mathrm{a}-\mathrm{O} 3 \mathrm{a} 1^{\mathrm{ix}}$ & $2.618(6)$ & $2.590(6)$ & $2.648(6)$ & $\mathrm{Na} 2 \mathrm{~b}-\mathrm{O} 3 \mathrm{a}^{\mathrm{vii}}$ & $2.660(6)$ & $2.605(6)$ & $2.714(6)$ \\
\hline $\mathrm{Na} 2 \mathrm{a}-\mathrm{O} 3 \mathrm{a} 2^{\mathrm{ix}}$ & 3.011 (10) & $2.966(10)$ & $3.055(10)$ & $\mathrm{Na} 2 \mathrm{~b}-\mathrm{O} 3 \mathrm{a} 2^{\mathrm{vii}}$ & $2.394(10)$ & $2.325(11)$ & 2.464 (11) \\
\hline $\mathrm{Na} 2 \mathrm{a}-\mathrm{O} 3 \mathrm{~b} 1^{\mathrm{iv}}$ & $2.540(5)$ & $2.477(5)$ & $2.607(5)$ & $\mathrm{Na} 2 \mathrm{~b}-\mathrm{O} 3 \mathrm{~b} 1$ & $2.828(5)$ & $2.680(5)$ & $2.972(5)$ \\
\hline $\mathrm{Na} 2 \mathrm{a}-\mathrm{O} 3 \mathrm{~b} 2^{\mathrm{iv}}$ & $2.892(8)$ & $2.843(9)$ & $2.941(9)$ & & $2.642(9)$ & & $2.659(9)$ \\
\hline $\mathrm{Na} 2 \mathrm{a}-\mathrm{O} 4 \mathrm{a} 1$ & 2.901 (4) & 2.831 & 2.971 & $\mathrm{Na} 2 \mathrm{~b}-\mathrm{O} 4 \mathrm{a} 1^{\mathrm{x}}$ & & & $2.514(4)$ \\
\hline $\mathrm{Na} 2 \mathrm{a}-\mathrm{O} 4 \mathrm{a} 2$ & $2.611(9)$ & $2.563(10)$ & $2.659(10)$ & $\mathrm{Na} 2 \mathrm{~b}-\mathrm{O} 4 \mathrm{a} 2^{\mathrm{x}}$ & $2.922(8)$ & $2.888(7)$ & $2.957(8)$ \\
\hline $\mathrm{Na} 2 \mathrm{a}-\mathrm{O} 4 \mathrm{~b} 1^{\mathrm{ii}}$ & $2.486(5)$ & $2.468(5)$ & $2.506(5)$ & $\mathrm{Na} 2 \mathrm{~b}-\mathrm{O} 4 \mathrm{~b} 1$ & $2.879(5)$ & $2.781(5)$ & $2.977(5)$ \\
\hline $\mathrm{Na} 2 \mathrm{a}-\mathrm{O} 4 \mathrm{~b} 2^{\mathrm{ii}}$ & $2.862(8)$ & $2.815(8)$ & $2.909(8)$ & $\mathrm{Na} 2 \mathrm{~b}$ & $2.637(8)$ & $2.600(8)$ & $2.672(8)$ \\
\hline $\mathrm{Na} 2 \mathrm{a}-\mathrm{O} 5 \mathrm{a}^{\mathrm{ix}}$ & $2.612(3)$ & $2.532(3)$ & $2.695(3)$ & $\mathrm{Na} 2 \mathrm{~b}-\mathrm{O} 5 \mathrm{~b}^{\mathrm{xi}}$ & $2.476(3)$ & $2.433(3)$ & $2.520(3)$ \\
\hline $\mathrm{Na} 2 \mathrm{a}-\mathrm{Ob}^{\mathrm{ix}}$ & $2.473(3)$ & $2.460(3)$ & $2.485(3)$ & $\mathrm{Na} 2 \mathrm{~b}-\mathrm{O} 6 \mathrm{~b}^{\mathrm{xi}}$ & 2.549 (3) & $2.523(3)$ & $2.575(3)$ \\
\hline
\end{tabular}

Symmetry codes: (i) $-x_{2}, x_{1}-x_{2}, x_{3}$; (ii) $x_{1}+2 / 3, x_{2}+1 / 3, x_{3}$; (iii) $x_{1}, x_{2}, x_{3}+1$; (iv) $x_{1}+2 / 3, x_{2}+1 / 3, x_{3}+1$; (v) $\quad x_{1}-2 / 3, x_{2}-1 / 3, x_{3}-1$; (vi) $\quad-x_{2}, x_{1}-x_{2}, x_{3}+1 ; \quad$ (vii) $\quad-x_{2}, x_{1}-x_{2}, x_{3}-1$; $\quad$ (viii) $-x_{1}+x_{2}+1 / 3,-x_{1}-1 / 3, x_{3}+1 ; \quad$ (ix) $\quad-x_{2}+2 / 3, x_{1}-x_{2}+1 / 3, x_{3}$; $\quad$ (x) $\quad x_{1}-2 / 3, x_{2}-1 / 3, x_{3}$; $\quad$ (xi) $-x_{2}-2 / 3, x_{1}-x_{2}-1 / 3, x_{3}$.

their standard deviations. The two groups were modulated as complementary [occupation probability(Group II) $=1-$ occupation probability(Group I)], so that in the refinement only three additional parameters had to be taken into account to describe the occupational modulation for the 12 atomic positions.

Refinement taking into account modulation of the atomic displacement parameters did not lead to an improvement of the overall agreement factors and was therefore discarded. In general, modulation parameters which were below three times their standard deviation, were set to zero and not refined any further.

Final agreement factors are given in Table 2. Atomic coordinates and amplitudes of displacive modulation have been deposited; amplitudes of occupational modulation are given in Table 3. Selected interatomic distances are given in Tables 4 and 5; $\mathrm{O}-T-$ $\mathrm{O}$ angles are provided in the supplementary material.

\subsection{The final model of the average structure in $P 3$}

The refinement of the incommensurately modulated structure shows that split-atom positions should be taken into account for the atoms $\mathrm{O} 1 \mathrm{a} / \mathrm{O} 1 \mathrm{~b}, \mathrm{O} 2 \mathrm{a} / \mathrm{O} 2 \mathrm{~b}, \mathrm{O} 3 \mathrm{a} / \mathrm{O} 3 \mathrm{~b}$ and $\mathrm{O} 4 \mathrm{a} / \mathrm{O} 4 \mathrm{~b}$ and, in addition, the cationic positions in the large, hexagonal channels are slightly shifted from the threefold rotation axis. The average structure was therefore rerefined in the space group $P 3$ in combination with a twinning operation corresponding to a mirror plane perpendicular to $\mathbf{c}^{4}$ For this the new model of the average structure, which takes into account all the split-atom positions identified in the higher-dimensional refinement, was derived from the incommensurate structure using the corresponding option in $J A N A 2006$. The refinement led to a significant decrease of the overall agreement factors when compared with those in space group $\mathrm{P6}_{3}$ (see Table 1). Fig. 7 shows partial projections of this average structure (referred to the large centered unit cell in $X 3)$. Atomic coordinates and displacement parameters are given in the supplementary material.

\section{Results and discussion}

The modulated structure of nepheline crystallizes as trigonal in the superspace group $X 3(00 \gamma) 0$ with $X=(0,0,0,0)$, $(1 / 3,2 / 3,0,2 / 3),(2 / 3,1 / 3,0,1 / 3)$ [standard 
setting $\left.P 3\left(\frac{1}{3} \frac{1}{3} \gamma\right) 0\right]$. The observed modulation wavevector is $\mathbf{q}=0.2048 \mathbf{c}^{*}$. A centered unit cell with a three times larger volume than in the usual description of the average structure was chosen to avoid rational components of the $\mathbf{q}$ vector (see Table 2). All of the atoms within the structure are affected by displacive modulations. In all cases first-order harmonics proved sufficient to describe the displacements of the atoms. Displacements are generally very small and do not exceed $0.1 \AA$. There is no indication of a reduced occupancy or occupational modulation for the $\mathrm{Na}^{+}$ions incorporated in the small oval channel. As a consequence, it follows from the chemical composition that the larger pseudohexagonal channels incorporate $0.54 \mathrm{~K}^{+}+0.24 \mathrm{Na}^{+}+0.03 \mathrm{Ca}^{2+}+0.19$ vacancies.

The electron density for the cationic positions (K1a, K1b) in the large, pseudohexagonal channels is shown in Fig. 4, where the refined displacive modulation in the direction of $x_{3}$ is indicated. As can be seen from the figure, the electron density
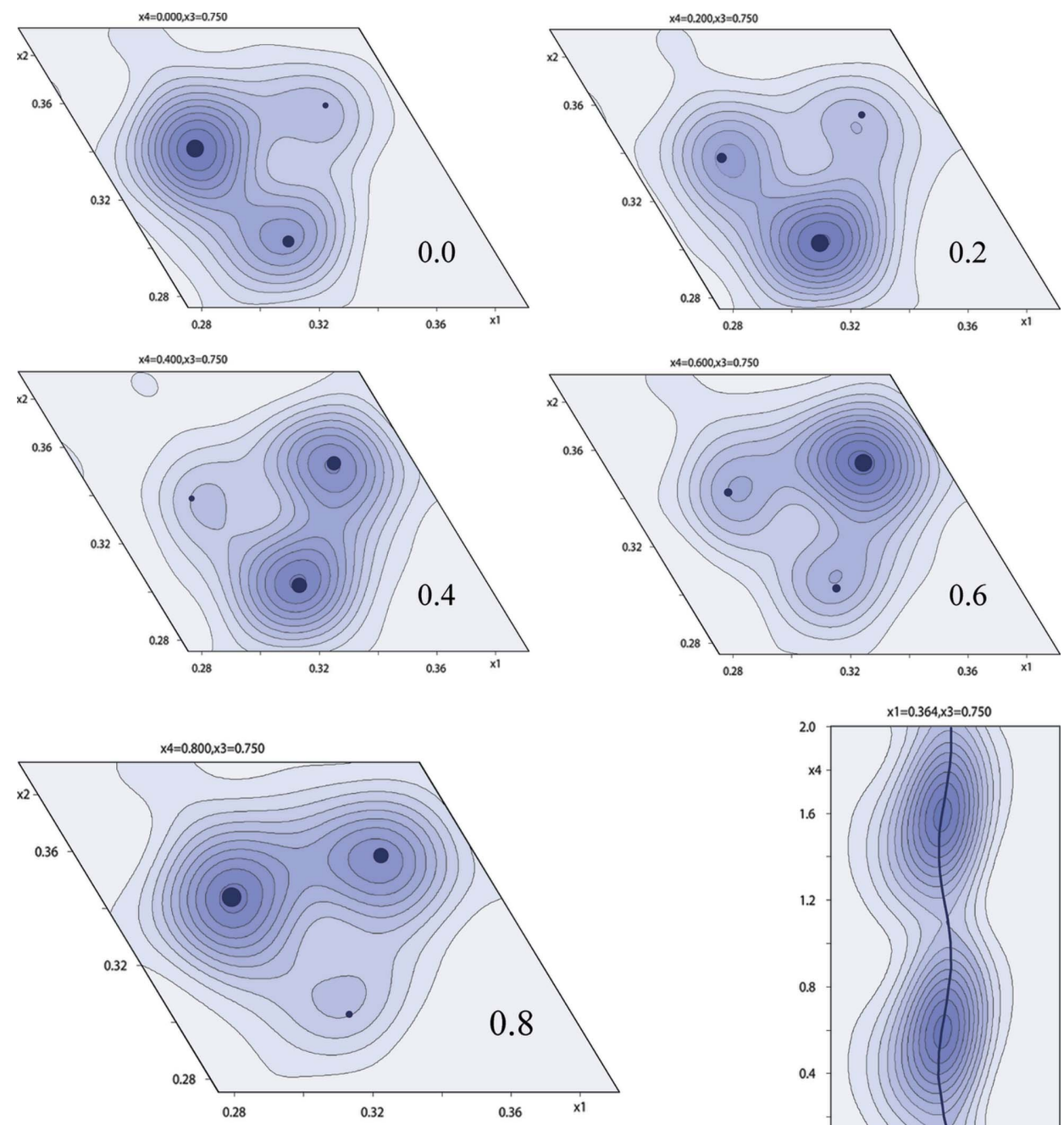

Figure 6

$F$ (obs) Fourier maps around the O1a position. Cuts are at different values of $t(0,0.2,0.4,0.6,0.8)$. The three equivalent O1a positions are indicated. The figure in the lower right corner represents the $x_{2}-t$ plane of the electron density of one O1a position $\left(x_{1}=0.364, x_{3}=0.75\right)$. The displacive modulation function is indicated (contour lines 1 e $\AA^{-1}$ in all figures).

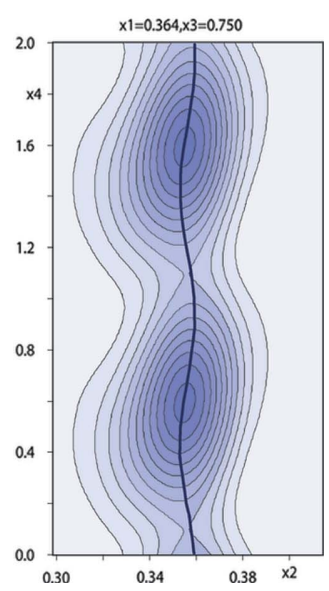

around the cationic position shows a small fluctuation indicating that occupational modulation is present, but not very pronounced. Indeed the small values of the refined amplitudes (Table 3 and Fig. 8) imply that the distribution of the different cations and the vacancies in the structure are characterized by a high degree of disorder. Complete ordering of the different cations or ordering of vacancies (and the subsequent coupling to the displacive modulations of the tetrahedral framework) mechanisms which, according to earlier studies on the average structure, were supposed to be related to the formation of the modulated structure (Foreman \& Peacor, 1970; McConnell, 1981; Merlino, 1984; Angel et al., 2008) - can therefore be excluded on the basis of our structure determination. Fig. 5 shows cuts of the electron density around K1a (the electron density around $\mathrm{K} 1 \mathrm{~b}$ looks similar) at various values of $t$, in which the refined positions are indicated. As can be seen, at certain values of $t(e . g . t=0.4)$ the cations lie nearly on the special position $\left(0,0, x_{3}\right)$, while at other values of $t$ they are clearly displaced. It is noteworthy that the maximum displacement from the $0,0, x_{3}$ position approximately coincides with the maximum occupancy.

The bond-valence sums for the cations (Fig. 9) were calculated on the basis of the parameters from Brese \& O'Keeffe (1991). While variations as a function of $t$ are relatively limited for the $\mathrm{Na}^{+}$ ions in the smaller oval channels [Na2a: $0.846(4) \longrightarrow$ 0.909 (4) v.u.; Na2b: 0.901 (4) $\longrightarrow 0.924$ (4) v.u.], variations for the K1a and K1b position are significantly larger [K1a: 0.872 (6) $\longrightarrow 1.005$ (7) v.u.; K1b: $\quad 0.827(5) \quad \longrightarrow$ 1.045 (8) v.u. calculated on the basis of bond valence parameters for $\mathrm{K}-\mathrm{O}$ ]. The increase in bond-valence sums around the values of $t \simeq 0.2-0.25$ for $\mathrm{K} 1 \mathrm{a}$ and the respective decrease at $t \simeq 0.7-0.75$ is mainly due to the large variation of the shortest $\mathrm{K} 1 \mathrm{a}-\mathrm{O}$ bonds (K1a-O2a) (Table 5). In a similar way, the maxima and minima in the bondvalence sums for $\mathrm{K} 1 \mathrm{~b}$ (at $t \simeq 0.33$ and $t \simeq 0.83$ ) can be attributed to variations in the $\mathrm{K} 1 \mathrm{~b}-\mathrm{O} 2 \mathrm{~b}$ bonds. At $t$ values corresponding to the bondvalence sum maxima $(t \simeq 0.20$ 
0.25), the occupancies for the $\mathrm{K}$ positions show their minimum values. These observations suggest that the smaller $\mathrm{Na}$ ions are concentrated around these regions of $t$, while the larger $\mathrm{K}$ ions probably prefer the sites close to $t$ values of $0.70-0.75$, where the occupancy shows a maximum and the bond-valence sums reach a minimum.

According to earlier suggestions based on the refinement of the average structure, the oxygen atom located on the threefold rotation axis should be displaced from its special position and is usually described as a split atom position in the refinements of the average structure. In the modulated structure these atomic positions, designated $\mathrm{O} 1 \mathrm{a}$ and $\mathrm{O} 1 \mathrm{~b}$ in
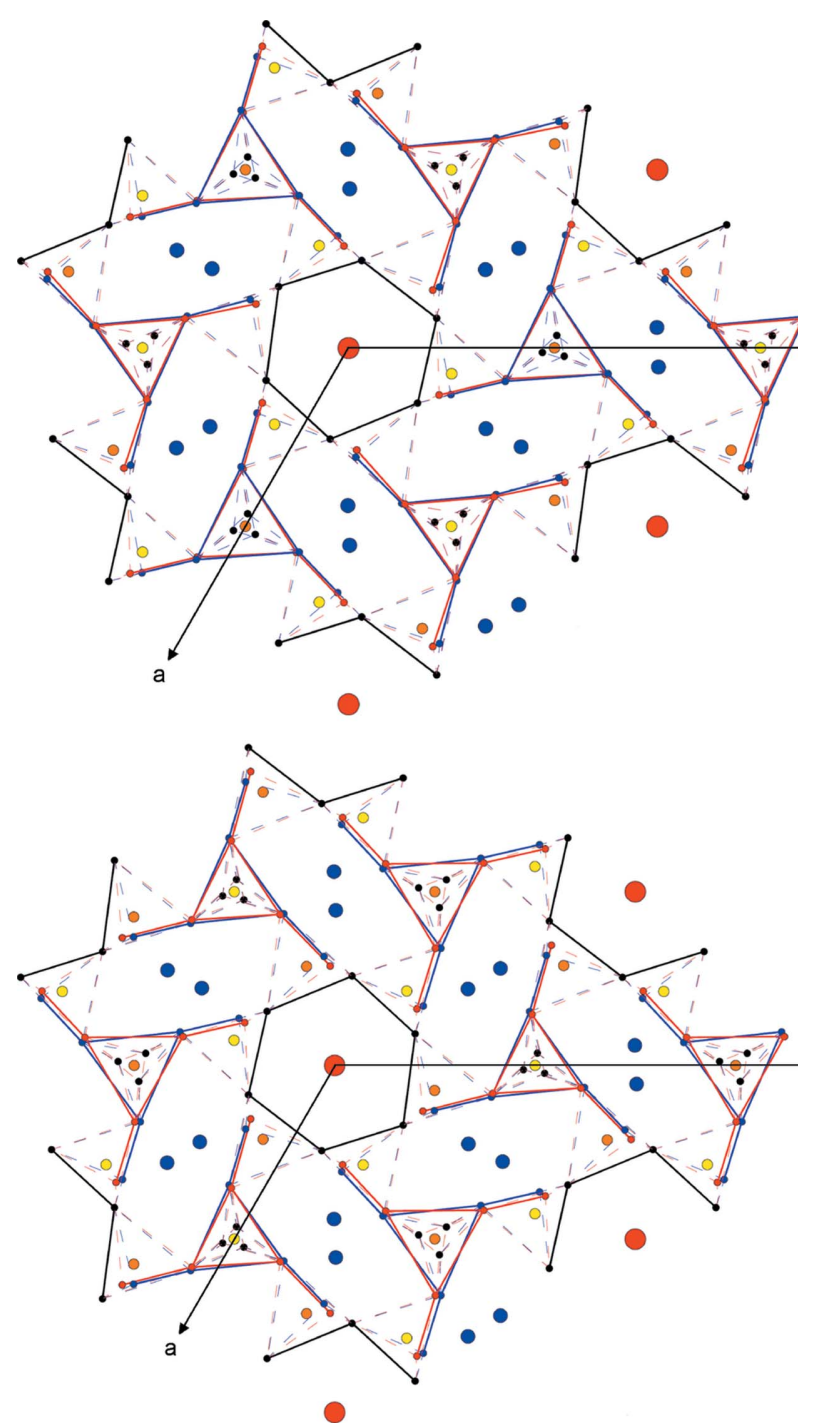

\section{Figure 7}

Partial projection along [001] of the average structure of nepheline (space group $P 3$ ) illustrating the disorder in the tetrahedral layers. (top) limits $z=-0.25 \longrightarrow 0.25$ (bottom) $z=0.25 \longrightarrow 0.75$. Cations in the channels are drawn in red $(\mathrm{K})$ and blue $(\mathrm{Na})$, tetrahedral cations are indicated in orange ( $\mathrm{Al}$ ) and yellow (Si). O1a, O1b, O5a, O5b, O6a and O6b atoms, and tetrahedral edges between them are indicated in black; $\mathrm{O}$ atoms of group I and tetrahedral edges formed by them are shown as blue circles and solid blue lines, atoms of group II and the corresponding edges are shown in red. Tetrahedral edges formed by atoms of group I or II and the remaining $\mathrm{O}$ atoms are indicated by broken lines. this work, are also clearly displaced from the threefold axis and are in addition affected by an occupational modulation (Fig. 6). Occupational modulation amplitudes are significantly larger than for the cationic positions (Table 5 and Fig. 8). The separation of the different maxima when viewed as a function of $t$ are, however, not large enough to assume a crenel-like modulation function so that a completely ordered pattern of occupation of the three maxima can be excluded. Instead the occupation probabilities of the three positions vary as a function of $t$.

If one imagines the three different oxygen positions as the top atoms of the tetrahedra (see Fig. 7, where O1a and O1b are indicated as black circles), it is reasonable to assume on the basis of the usually fairly rigid nature of tetrahedral units in alumosilicates that other $\mathrm{O}$ atoms belonging to the same tetrahedra also have to be split into more than one position. In fact, if one assumes only a single position for atoms $\mathrm{O} 2, \mathrm{O} 3$ and $\mathrm{O} 4$, the tetrahedral $\mathrm{O}-T-\mathrm{O}$ angles in the Al1/Si1 and $\mathrm{Al} / \mathrm{Si} 2$ tetrahedra deviate strongly from the common values

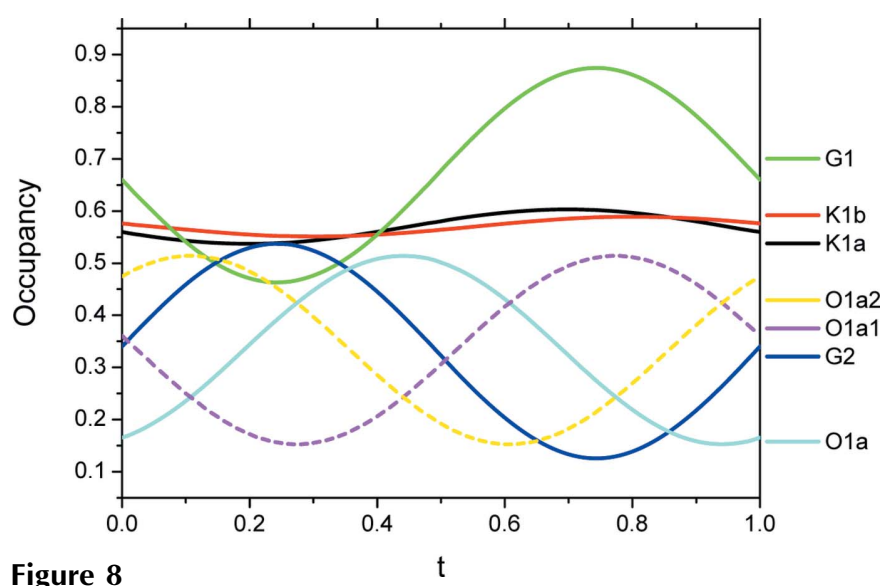

Figure 8

Occupational modulation of the atoms. G1 represents atoms O2a1, O2b1, O3a1, O3b1, O4a1 and O4b1; G2 represents O2a2, O2b2, O3a2, O3b2, $\mathrm{O} 4 \mathrm{a} 2$ and $\mathrm{O} 4 \mathrm{~b} 2$. Occupational modulation of atom O1a is identical to atom O1b. Occupational modulation of symmetry-related positions of $\mathrm{O} 1 \mathrm{a}$ and $\mathrm{O} 1 \mathrm{~b}$ are indicated by broken lines.

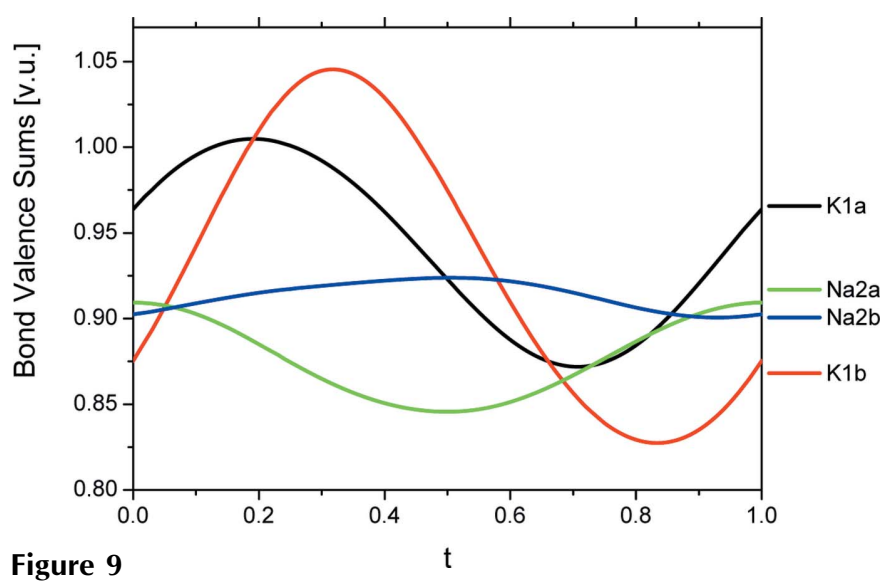

Bond-valence sums of the monovalent cations as a function of the internal coordinate $t$. Bond-valence parameters have been taken from Brese \& O'Keeffe (1991). Bond-valence sums for the K1a/K1b position have been calculated on the basis of the bond-valence parameters for $\mathrm{K}$. 
known for alumosilicates. In addition, displacement parameters for these atoms get very large, despite the fact that displacive modulation has already been taken into account, indicating that the model is not altogether satisfactory. Indeed, an analysis of the Fourier and difference-Fourier maps around these oxygen positions showed that two distinct positions for each of these atoms can be identified (denoted as O2a1/O2a2, $\mathrm{O} 2 \mathrm{~b} 1 / \mathrm{O} 2 \mathrm{~b} 2$ etc.) and they were consequently introduced in the refinement. As explained above, occupational modulation parameters of these different $\mathrm{O}$-atom positions proved to be related. Thus, two groups of $\mathrm{O}$ atoms are formed: Group 1 is composed of O2a1, O2b1, O3a1, O3b1, O4a1 and O4b1, and group 2 of O2a2, O2b2, O3a2, O3b2, O4a2 and O4b2. In Fig. 7, which shows part of the final model of the average structure of nepheline in the space group $X 3$, these two groups of atoms are indicated. Tetrahedral edges between atoms belonging to the same group are indicated by full lines in the figure, other edges by broken lines. Occupational modulation within one group of atoms is identical; occupational modulations between the two groups are complementary (Fig. 8). The sum of the occupancies of both groups is 1 for all values of $t$. The amplitudes of the occupational modulations are considerable, leading to values larger than 0.8 for the occupation of group I ( $\equiv$ lower than 0.2 for group II). The fact that occupational modulation for the atoms within one group refined to identical values implies that these groups of atoms behave as quasi-rigid units, i.e. if one of the atomic positions of the group has a certain occupation at a value of $t$ the other atoms of the group have the same occupation probability.

As can be seen from the refinement, there is an additional correlation between the occupational modulation of the oxygen positions $\mathrm{O} 1 \mathrm{a}$ and $\mathrm{O} 1 \mathrm{~b}$, and the occupational modulations of the two groups of atoms: at values of $t$ where one of the symmetry-equivalent positions of O1a (O1a1 in Fig. 8) reaches its maximum occupancy of approximately 0.5 , the occupancy for group I is also close to its maximum, i.e. the occupational modulations are in phase. Of course, at the same time the occupancy for group II shows a minimum (Fig. 8). This suggests that the occupancy of selected $\mathrm{O} 1 \mathrm{a}$ or $\mathrm{O} 1 \mathrm{~b}$ positions leads to the occurrence or avoidance of atomic positions of group I or II in the structure. Indeed a close inspection of geometrical parameters of the tetrahedra supports this hypothesis as the 'avoided positions' are generally characterized by unfavorable geometrical characteristics (see table with $\mathrm{O}-T-\mathrm{O}$ angles in the supplementary material).

Bond-valence sums (Fig. 10) and $T-\mathrm{O}$ distances (Table 4) indicate a very high degree of order for the tetrahedral $\mathrm{Al}^{3+}$ and $\mathrm{Si}^{4+}$ cations in agreement with earlier results on the average structure (Sahama, 1962; Dollase \& Peacock, 1971; Dollase \& Thomas, 1978; Gregorkiewitz, 1984; Stebbins et al., 1986; Tait et al., 2003). Assuming that the simultaneous occupation of $\mathrm{O}$-atom positions leading to unfavorable geometry is avoided, tetrahedral angles are in good agreement with values from the literature.

It is not possible to identify the site into which the excess $\mathrm{Si}^{4+}$ is incorporated in the structure, as variations of $T-\mathrm{O}$ distances and bond-valence sums for the $\mathrm{AlO}_{4}$ tetrahedra are too small to obtain a reliable hint. We can however, definitely exclude an ordered incorporation of $\mathrm{Si}^{4+}$ into the tetrahedra primarily occupied by $\mathrm{Al}^{3+}$. Furthermore, our data provide no indication for the formation of domains with different $\mathrm{Al} / \mathrm{Si}$ ordering patterns as suggested by McConnell (1962) and we can therefore exclude another of the mechanisms which was suggested to be at the origin of the formation of the modulated structure.

Another explanation given in the literature for the formation of the modulated structure is the displacive modulation of the essentially rigid tetrahedra of the framework (Parker \& McConnell, 1971; Parker, 1972; Hayward et al., 2000). This explanation is based on the assumption that the large atomic displacement parameters of part of the $\mathrm{O}$ atoms of the framework (especially $\mathrm{O} 1$, but also $\mathrm{O} 2, \mathrm{O} 3$ and $\mathrm{O} 4$ ) hide an underlying displacive modulation. However, the refinement of the modulated structure shows that the better way to adjust these atomic positions are occupational modulation functions with considerable amplitudes between three (in the case of O1; Fig. 6) or two (in the case of $\mathrm{O} 2, \mathrm{O} 3$ and O4) complementary positions. In contrast, the displacive modulation functions for these $\mathrm{O}$ atoms have very small amplitudes and are not especially important to reproduce the satellite inten-
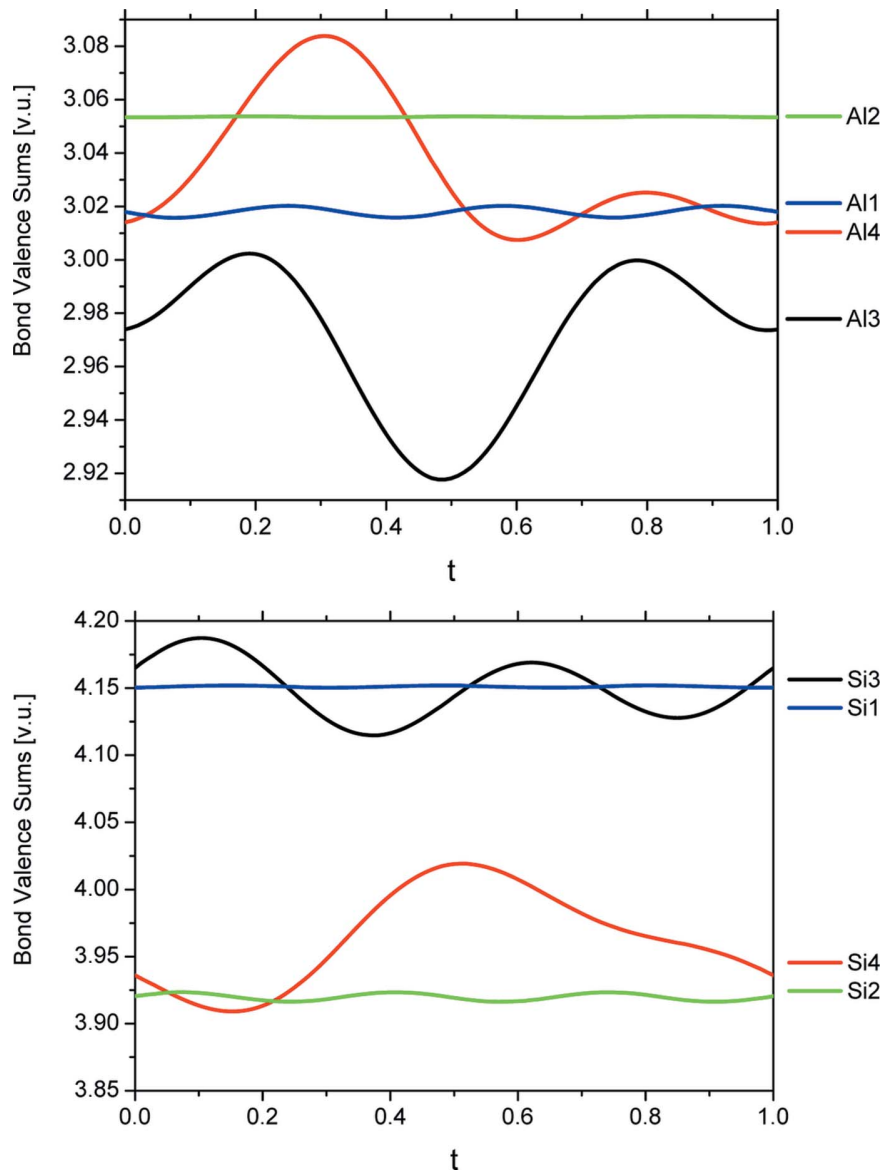

Figure 10

Bond-valence sums of the tetrahedral cations as a function of the internal coordinate $t$. Bond-valence parameters have been taken from Brese \& O'Keeffe (1991). 
sities in a satisfactory way. If, for example, one assumes that the $\mathrm{O} 1$ atom is not affected by displacive modulation at all, the overall agreement factor for the satellites increases by less than $0.5 \%$. Indeed, even for the average structure in $P 3$ the introduction of the split-atom positions for $\mathrm{O} 2, \mathrm{O} 3$ and $\mathrm{O} 4$ (derived from the incommensurate structure) reduces the agreement factors considerably (Table 1). It is, however, noteworthy that groups of tetrahedral cations and $\mathrm{O}$ atoms which are not affected by occupational modulation (O5a/ $\mathrm{O} 5 \mathrm{~b}, \mathrm{O} 6 \mathrm{a} / \mathrm{O} 6 \mathrm{~b})$ do indeed behave like rigid groups, as the corresponding $T-\mathrm{O}$ distances and $\mathrm{O}-T-\mathrm{O}$ angles have minimal variations as a function of $t$ (Table 4).

Although we can exclude coupling of the ordered distribution of vacancies in the channel with the displacive modulation of the framework as suggested by Angel et al. (2008), a correlation between the modulations of the framework and the cationic positions is present in the structure. Thus, the maximum occupancy for the cationic positions around $t \simeq$ 0.70-0.75 coincides with the maximum occupancy for the atoms of group I, while the maximum occupancy for the atoms of group II at $t \simeq 0.20-0.25$ coincides with the minimum occupancy for the cationic positions. Cations incorporated in the large, pseudohexagonal channels are coordinated by nine $\mathrm{O}$ atoms. While six of the coordinating $\mathrm{O}$ atoms are not affected by occupational modulation (K1a: $3 \times$ O5a and $3 \times$ O6a; K1b: $3 \times$ O5b and $3 \times$ O6b), the three additional $\mathrm{O}$ atoms occupy two possible positions (K1a: $3 \times \mathrm{O} 2 \mathrm{a} 1 / \mathrm{O} 2 \mathrm{a} 2$; $\mathrm{K} 1 \mathrm{~b}: 3 \times \mathrm{O} 2 \mathrm{~b} 1 / \mathrm{O} 2 \mathrm{~b} 2$ ), which belong either to group I or group II. Interatomic distances between the cations and the $\mathrm{O}$ atoms belonging to groups I and II are different: while distances from atoms $\mathrm{O} 2 \mathrm{a} 1$ and $\mathrm{O} 2 \mathrm{~b} 1$ to the cations vary from 2.964 (9) to 3.233 (9) $\AA$, distances involving atoms O2a2 and O2b2 atoms are considerably shorter [2.809(11)-2.947(10) $\AA$ ]. Bondvalence sums for $\mathrm{K}^{+}$in the large pseudohexagonal channel are close to the ideal values (9) and even exceed the values of 1 in certain regions of $t$, yet the incorporation of the smaller $\mathrm{Na}^{+}$in this channel implies strong underbonding at any value of $t$. This underbonding can be at least partially improved if the $\mathrm{O} 2 \mathrm{a} 2$ and $\mathrm{O} 2 \mathrm{~b} 2$ positions, which form shorter bonds to the cationic positions, are favored over the $\mathrm{O} 2 \mathrm{a} 1$ and $\mathrm{O} 2 \mathrm{~b} 1$ positions, which are at longer distances. The preferential incorporation of $\mathrm{Na}^{+}$in regions of $t \simeq 0.2-0.25$ would thus favor the occupation of positions $\mathrm{O} 2 \mathrm{a} 2$ and $\mathrm{O} 2 \mathrm{~b} 2$, and - owing to the geometrical characteristics of the tetrahedra - of the other atomic positions of group II.

\section{Conclusions}

The incommensurately modulated structure of nepheline has been determined in $(3+1)$-dimensional space using the superspace algorithm. All atoms in the structure are affected by displacive modulation with amplitudes which are in general not larger than $0.1 \AA$. The large pseudohexagonal channels are occupied by $\mathrm{K}^{+}, \mathrm{Na}^{+}$and vacancies in a strongly disordered manner, although an occupational modulation with a small amplitude has to be taken into account for these positions. A large part of the $\mathrm{O}$ atoms are approximated by split-atom positions, which are additionally affected by occupational modulation resulting in a high degree of disorder in the modulated structure. Occupational probabilities for the splitatom positions are complementary. A coupling between the occupational modulations of the cationic positions in the pseudohexagonal channel and the occupational modulations of the framework atoms is present. In addition, a correlation between occupational modulations and displacive modulations can be observed.

We thank Ross Angel for supplying us with the crystal investigated in this study. Furthermore, we thank him, Volker Kahlenberg and Tonči Balić Žunič for helpful discussions. This work has been supported by the European Mineral Sciences Initiative of the European Science Foundation (project EuroMinSci-ORION). We acknowledge financial support by the Spanish Ministerio de Educación y Ciencia (Acción Complementaria CGL2005-25095-E/BTE), the Ministerio de Ciencia y Innovación (Proyecto I+D FIS2008-03834), the Gobierno Vasco and the Praemium Academiae of the Czech Academy of Sciences. WM acknowledges financial support from the BMBF, Germany (Project 05KS7RF1). Portions of this research were carried out at the light source DORIS III at DESY. DESY is a member of the Helmholtz Association (HGF). The research leading to these results has received funding from the European Community's Seventh Framework Programme (FP7/2007-2013) under grant agreement No. 226716.

\section{References}

Angel, R. J., Gatta, C. D., Boffa-Ballaran, T. \& Carpenter, M. (2008). Can. Mineral. 46, 1465-1476.

Becker, P. J. \& Coppens, P. (1974). Acta Cryst. A30, 129-147.

Bindi, L. \& Bonazzi, P. (2003). Phys. Chem. Miner. 30, 523-526.

Bindi, L. \& Bonazzi, P. (2005). Phys. Chem. Miner. 32, 89-96.

Bindi, L., Bonazzi, P., Dušek, M., Petř́íček, V. \& Chapuis, G. (2001). Acta Cryst. B57, 739-746.

Bindi, L., Czank, M., Röthlisberger, F. \& Bonazzi, P. (2001). Am. Mineral. 86, 747-751.

Bindi, L., Dušek, M., Petříček, V. \& Bonazzi, P. (2006). Acta Cryst. B62, 1031-1037.

Bolotina, N. B. (2006). Crystallogr. Rep. 51, 1034-1042.

Bolotina, N. B., Rastsvetaeva, R. K. \& Sapozhnikov, A. N. (2006). Crystallogr. Rep. 51, 589-595.

Brese, N. E. \& O'Keeffe, M. (1991). Acta Cryst. B47, 192-197.

Dollase, W. A. \& Peacock, D. R. (1971). Contrib. Mineral. Petrol. 30, 129-134.

Dollase, W. A. \& Thomas, V. M. (1978). Contrib. Mineral. Petrol. 66, 311-318.

Dowty, E. (1997). ATOMS, Version 5.0.7. Shape Software, Kingsport, USA.

Foreman, N. \& Peacor, D. R. (1970). Z. Kristallogr. 132, 45-70.

Gatta, G. D. \& Angel, R. J. (2007). Am. Mineral. 92, 1446-1455.

Gregorkiewitz, M. (1984). Bull. Mineral. 107, 499-507.

Hahn, T. \& Buerger, M. J. (1955). Z. Kristallogr. 106, 308-338.

Hassan, I. (2000). Am. Mineral. 85, 1383-1389.

Hassan, I., Antao, S. M. \& Hersi, A. A. M. (2003). Can. Mineral. 41, 759-783.

Hassan, I., Antao, S. M. \& Parise, J. B. (2004). Mineral. Mag. 68, 499513. 
Hassan, I. \& Buseck, P. R. (1989). Am. Mineral. 74, 394-410.

Hayward, S., Pryde, A. K. A., de Dombal, R. F., Carpenter, M. A. \& Dove, M. T. (2000). Phys. Chem. Miner. 27, 285-290.

Janner, A. \& Janssen, T. (1980a). Acta Cryst. A36, 399-408.

Janner, A. \& Janssen, T. (1980b). Acta Cryst. A36, 408-415.

McConnell, J. D. C. (1962). Mineral. Mag. 33, 114-124.

McConnell, J. D. C. (1981). Am. Mineral. 66, 990-996.

Merlini, M., Gemmi, M. \& Artioli, G. (2005). Phys. Chem. Miner. 32, 189-196.

Merlino, S. (1984). Feldspars and Feldspathoids. Structures, Properties and Occurrences. NATO Advanced Study Institutes, Series C: Mathematical and Physical Sciences, edited by W. L. Brown, Vol. 137, pp. 435-470. Reidel: Dordrecht.

Parker, J. M. (1972). Z. Kristallogr. 136, 255-272.

Parker, J. M. \& McConnell, J. D. C. (1971). Nature Phys. Sci. 234, 178179.

Petříček, V., Dušek, M. \& Palatinus, L. (2006). JANA2006. Praha, Czech Republic.
Sahama, T. G. (1958). Am. Mineral. 43, 165-166.

Sahama, T. G. (1962). J. Petrol. 3, 65-81.

Schaper, A. K., Schosnig, M., Kutoglu, A., Treutmann, W. \& Rager, H. (2001). Acta Cryst. B57, 443-448.

Schreurs, A. M. M., Xian, X. \& Kroon-Batenburg, L. M. J. (2010). J. Appl. Cryst. 43, 70-82.

Stebbins, J. F., Murdoch, J. B., Carmichael, I. S. E. \& Pines, A. (1986). Phys. Chem. Miner. 13, 371-381.

Steurer, W. \& Jagodzinski, H. (1988). Acta Cryst. B44, 344351.

Tait, K. T., Sokolova, E., Hawthorne, F. C. \& Khomyakov, A. P. (2003). Can. Mineral. 41, 61-70.

Wolff, P. M. de (1974). Acta Cryst. A30, 777-785.

Wolff, P. M. de, Janssen, T. \& Janner, A. (1981). Acta Cryst. A37, 625636.

Xu, H. \& Veblen, D. R. (1995). Am. Miner. 80, 87-93.

Yamamoto, A., Nakazawa, H., Kitamura, M. \& Morimoto, N. (1984). Acta Cryst. B40, 228-237. 